\section{Smart technology for the surgery}

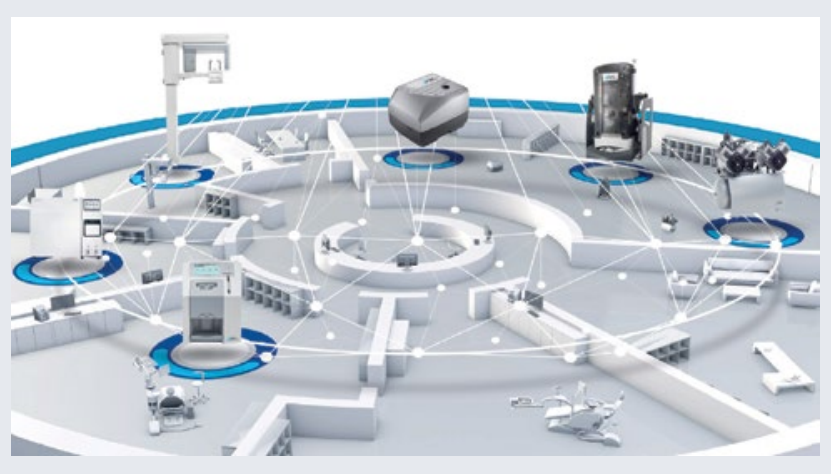

Many of us are using smart technology within the home, to control our heating, lighting or alarm systems. Now the same pioneering technology is available to make your working life as simple. Dürr Dental have launched their new IoT (internet of things) solution called VistaSoft Monitor, to ensure that the practice runs smoothly and intuitively.

This cloud-based IoT service solution allows all connectable Dürr Dental systems to be integrated into VistaSoft Monitor, providing a clear overview of all products, including compressors, autoclaves and $\mathrm{x}$-ray systems. The software is based on the following principle: monitor-transmit-analyse-act.

The units constantly monitor important operating parameters and transmit them in real time to VistaSoft Monitor, where they are analysed and then presented to the user in a clear format. Operation can be viewed centrally at a PC in the reception area, or decentralised in every treatment room or on a smartphone/ tablet via the corresponding app.

Potential problems are detected in advance, ie if the fill level of the amalgam collecting container is reaching its maximum an alert will be sent to ensure a replacement is ordered in plenty of time. The software will also flag issues that require an external response, such as a filter change on a compressor or a routine service of a piece of equipment. Operational reliability is thus ensured as the monitoring is being done through the wonders of IoT rather than relying on human assessment, leaving staff free to focus on what's most important - patients.

\section{Time-saving cephalometric exposure}

Dürr Dental have developed an extended version of their VistaVox S panoramic machine which contains six additional programmes for time-saving cephalometric exposure with minimum radiation doses, called VistaVox S Ceph.

Exceptional diagnostics and ease of use are guaranteed. Alongside the 17 panoramic programmes, the VistaVox S Ceph has several orthodontic applications, including 'Lateral Head', 'Full Lateral Head', 'PA Head' and 'Waters View'. With a scan time of just 1.9 seconds, images are exceptionally sharp using the lowest possible radiation dose. This functionality is afforded by the high-sensitivity CSL sensors. The unit can effortless switch between the 3D X-Ray and the Ceph boom, a process that on some machines can be both cumbersome and risky.

\section{Genuine valuation of your dental scrap}

Dentists quite rightly have concerns about disposing of their valuable scrap and one firm, MTD Metallurgical Co, offers dental professionals the ultimate safeguard of having a guaranteed valuation before deciding whether to sell their materials or receive them back in exactly the same condition in which MTD received them.

MTD Metallurgical Co is so confident about the amounts it pays out to dentists that they are offering their unique and genuine valuation service without charge.

While MTD Metallurgical Co use the latest technologies they always remain contactable; if a dentist has particular requirements or simply wants information not covered on the website the company is just a phone call away. The values of both gold and palladium have risen steeply and the prices MTD pay for gold and for palladium bonding alloy dental scrap crowns, inlays, bridges, posts, implant components and braces containing either or both of these metals have also steeply risen pro-rata.

MTD only deal directly with dental professionals so there are no reps or agents' costs and commissions deducted and MTD have no connection with any other company.

www.mtdpreciousmetals.com.

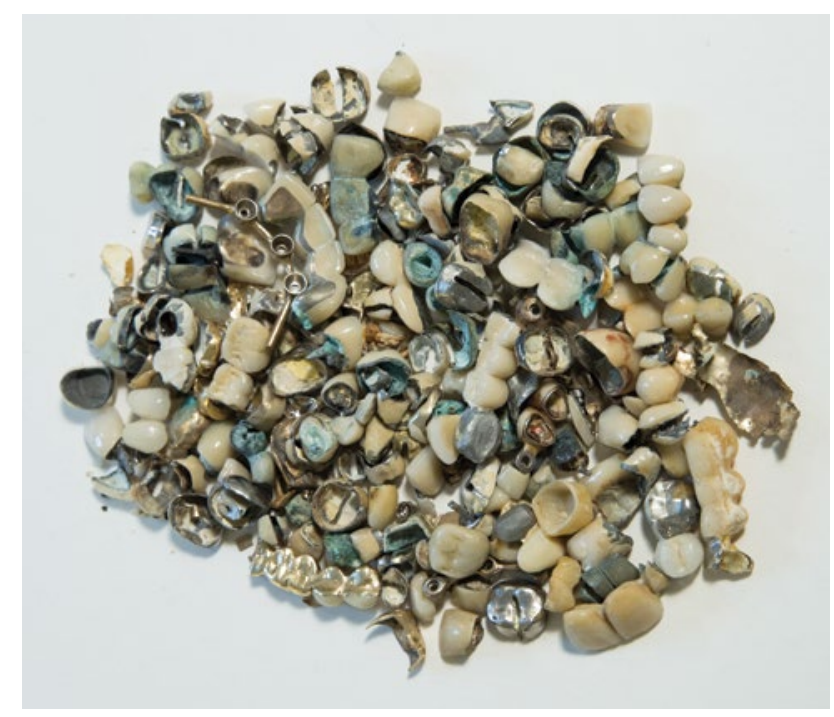

Just like the VistaVox $\mathrm{S}$ it has a perfect 3D imaging volume of $130 \mathrm{~mm}$ (compared to $80 \times 80 \mathrm{~mm}$ for most other systems). It completely covers the whole diagnostically relevant area, including the rear molars, an essential requirement for diagnosing an impacted wisdom tooth. Enhanced visibility does not require a higher radiation dose; the opposite is true. A special curved path, which rotates $540^{\circ}$, in combination with a tightly collimated fan beam and a highly sensitive Csl sensor, means that a particularly low radiation dose is used.

Similarly to the VistaVox S, this enhanced model offers $\varnothing 50 \mathrm{x}$ $50 \mathrm{~mm}$ volumes, for indications that only require a certain part of the jaw region to be shown. The unit offers true all-in-one capabilities for a full range of diagnostics. 